\title{
Global Deforestation
}

Christiane Runyan and Paolo D'Odorico. 2016. ISBN 978-1107-13526-0. Cambridge University Press, Cambridge, UK. US $\$ 91.95$ (hard cover)+ shipping. Contact: egerney@cambridge.org

lobal Deforestation provides a concise 6 but comprehensive examination of the variety of ways in which deforestation modifies environmental processes, as well as the societal implications of these changes. The book stresses how forest ecosystems may be prone to nearly irreversible degradation. To prevent the loss of important biophysical and socioeconomic functions, forests need to be adequately managed and protected against the increasing demand for agricultural land and forest resources. The book describes the spatial extent of forests, and provides an understanding of the past and present drivers of deforestation. It presents a theoretical background to understand the impacts of deforestation on biodiversity, hydrological functioning, biogeochemical cycling, and climate. It bridges the physical and biological sciences with the social sciences by examining economic impacts and socioeconomic drivers of deforestation. This book will appeal to advanced students, researchers and policymakers in environmental science, ecology, forestry, hydrology, plant science, ecohydrology, and environmental economics.
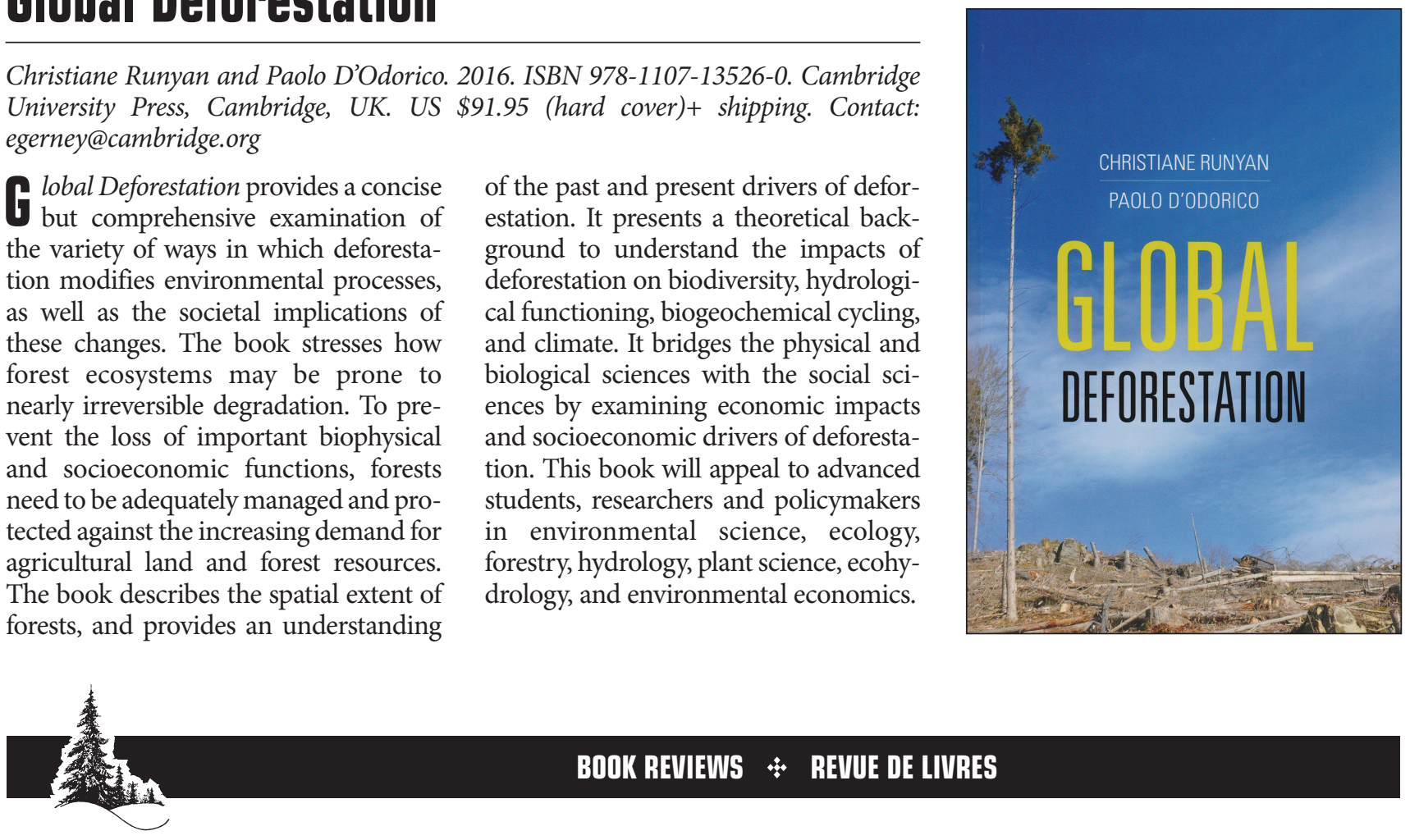

\section{Seeing Seeds - A Journey into the World of Seedheads, Pods, and Fruit}

Teri Dunn Chace. 2015. ISBN 978-1-60469-492-5 Thomas Allen \& Son, Markham, Ontario. 294 pgs. CAD \$39.95 + shipping. Contact:bonita.mok@t-allen.com

$\mathbf{T}^{\mathrm{h}}$ his is a beautifully illustrated book with photos created by "image stacking", a process which allows all parts of an object to be in sharp focus. The object, in this case a seed pod or fruit, is placed on a light table; several camera shots are taken from different angles and then pulled together using a special software program. The result is 'spectacular' pictures to illustrate the variability, complexities and often outright weirdness of the world of seeds and their various containers. Nothing is simple and straight-forward, and you wonder frequently why things are as they are. There are explanations of course-the seed is expected to float, drift on the wind, be eaten by birds or insects or transported by hitchhikers. They don't always explain "why things are so often complicated". Photographer Robert Llewellyn has more than 30 books featuring his work, including
Seeing Trees, selected as one of the best gardening books in 2011 by the New York Times.

Seeing Seeds is essentially divided into two sections. The first, for those of us who have forgotten our first-year Bio 110 , answers the questions-what are seeds, why do they exist, why are they so diverse, right up to what do seeds do and how do they do it. However, it is not only the seeds but their protective fleshy, papery or woody packaging that is so diverse and unusual. The text is by Teri Dunn Chace, author and editor of numerous articles on gardening and plant life. In this first section, she introduces some familiar terms such monoecious (male and female flower structures on the same plant) and dioecious (male and female flowers on separate plants). But then there is "apoximis" from the Greek, meaning "without intercourse"-also known as

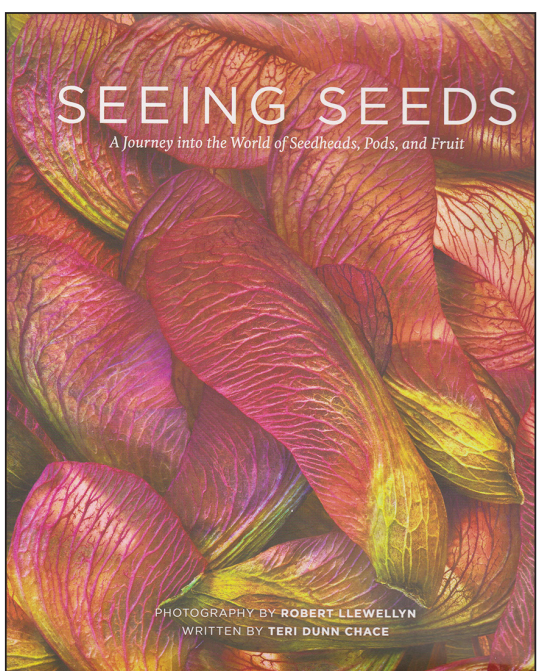

asexual reproduction. While this is a joyless situation, it is fortunately somewhat rare in nature. Some species of genera such as Crataegus, Amelanchier and Sorbus may indulge in this sad 
practice, if practice is the correct word. Chace notes that "dandelions are surprisingly quirky" with both male and female flower parts together but ignoring each other. Seeds grow directly from ovules, hence apoximis. Has this anything to do with the aggressiveness of these plants, and their ability to grow almost anywhere?

The second section of the book lends itself as a typical coffee table book, one that may be picked up and read at random. It is divided into five parts-garden flowers; weeds and wildflowers; herbs, spices, fibers and medicine; fruits and vegetables; and, shrubs and trees. The categories may seem unusual but only if you forget this book is about seeds and seed structures, and not about families and genera under a dendrological classification. Malus (apples) and Citrus (oranges) along with the tropical Tamarindus indica (a large, bushy tree with bean pods) are listed with fruits and vegetables; Malus (crabapples) and Rosa spp. are found with shrubs and trees. According to a note under "Acknowledgements", researchers at Kew Gardens in London, England estimate that "there are more than 400000 flowering plants in the world, all of which produce seeds." Chace and Llewellyn have done a remarkable job selecting and presenting some 100 representatives of this rich diversity of life. The nineteen selections of garden flowers, for example, include such favourites as Chinese lantern and larkspur but also the unusual semi-shrub, the Jewels of Opar (Talinum paniculatum), native to the southern USA, the Caribbean and the northern parts of South America. Chace gives an interesting origin to the common (or as she puts it "quirky") name to this species - too long to include here but it has something to do with one of Edgar Rice Burroughs' Tarzan stories. In fact, while the photographs are always striking, Chace's prose is factual without being overly scientific and is frequently surprising. For example, the original source of apples (Malus spp.) was the rugged hills of Kazakhstan and the repository of apple varieties maintained in Geneva, New York includes seeds and cuttings from these original trees. Arugula (Eruca vesicaria), a member of the cabbage family, is rich in vitamin $\mathrm{C}$ and potassium, and its tender young leaves are commonly used in salads (google "arugula"). However, "in Egypt, the plant is called gargeer and is considered a stimulant or aphrodisiac." In ancient Europe monks were forbidden from growing it their gardens, and an Arabic rhyme translates to "If the wife knew the secret of arugula, she would sow it under the bed."
The final section covers shrubs and trees and includes common species such as basswood and walnut but lesser known ones like the ear tree (Enterolobium cyclocarpum) and the screwbean mesquite (Prosopis pubescens). The common name of both will give you a good idea of what the seed pods look like. Also included and familiar to those who travel to tropical areas, is the jacaranda (Jacaranda mimosifolia), known for its flowers and mimosa or fern-like leaves, and whose fruit capsules are often turned into novel necklaces and earrings. Screwpine (Pandanus utlis) is a native of tropical coasts of the Pacific and Southeast Asia. The plant resembles a palm with long, strap-like leaves and the common name refers to the way the leaves are twisted near their base. The leaves are used for weaving baskets and mats, and to wrap rice, meat or fish prior to steaming in Thai and Filipino cooking.

Seeing Seeds is a beautiful book which should appeal to the gardener in all of us. And dipping through its pages one will come across observations to give a smile such as Fagus grandifolia offspring are known by foresters (some) as "sons of beeches".

Reviewed by

Ron Ayling, Chronicle editor
Advertise in/publier une annonce dans

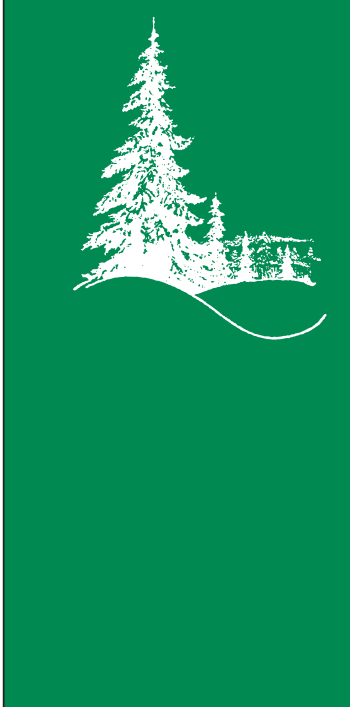

Forestry Chronicle
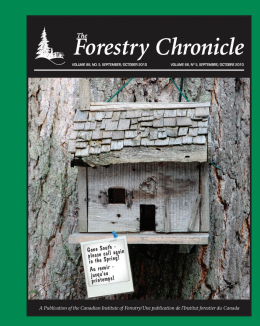

The Canadian Institute of Forestry/ Institut forestier du Canada c/o The Canadian Ecology Centre/(a/s) Centre écologique du Canada P.0. Box 99, 6905 Huy 17 West /C P. 99, 6905 route 17 Ouest, Mattawa, Ontario, Canada/Mattawa (Ontario) Canada $\mathrm{POH} 1 \mathrm{VO}$

Toll Free/Sans frais : 1-888-747-7577 • Tel/Tél : 613-744-1715

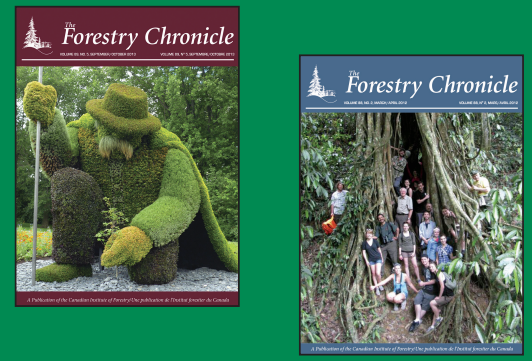

Email/courriel : admin@ciffifc.org

uruw,cifific.org 

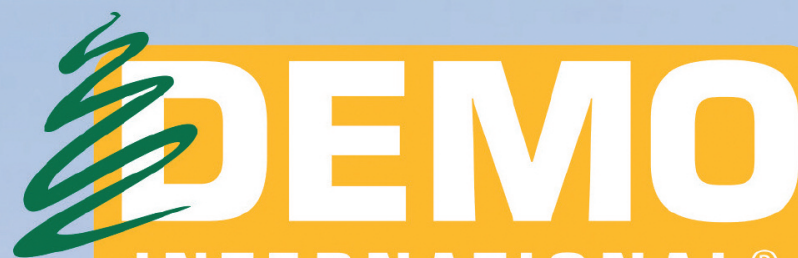

INTERNATIONAL

September 22-24, 2016

The Albion Fairgrounds - Maple Ridge, BC (23448 105 Ave, Maple Ridge, BC V2W 1B8) ine
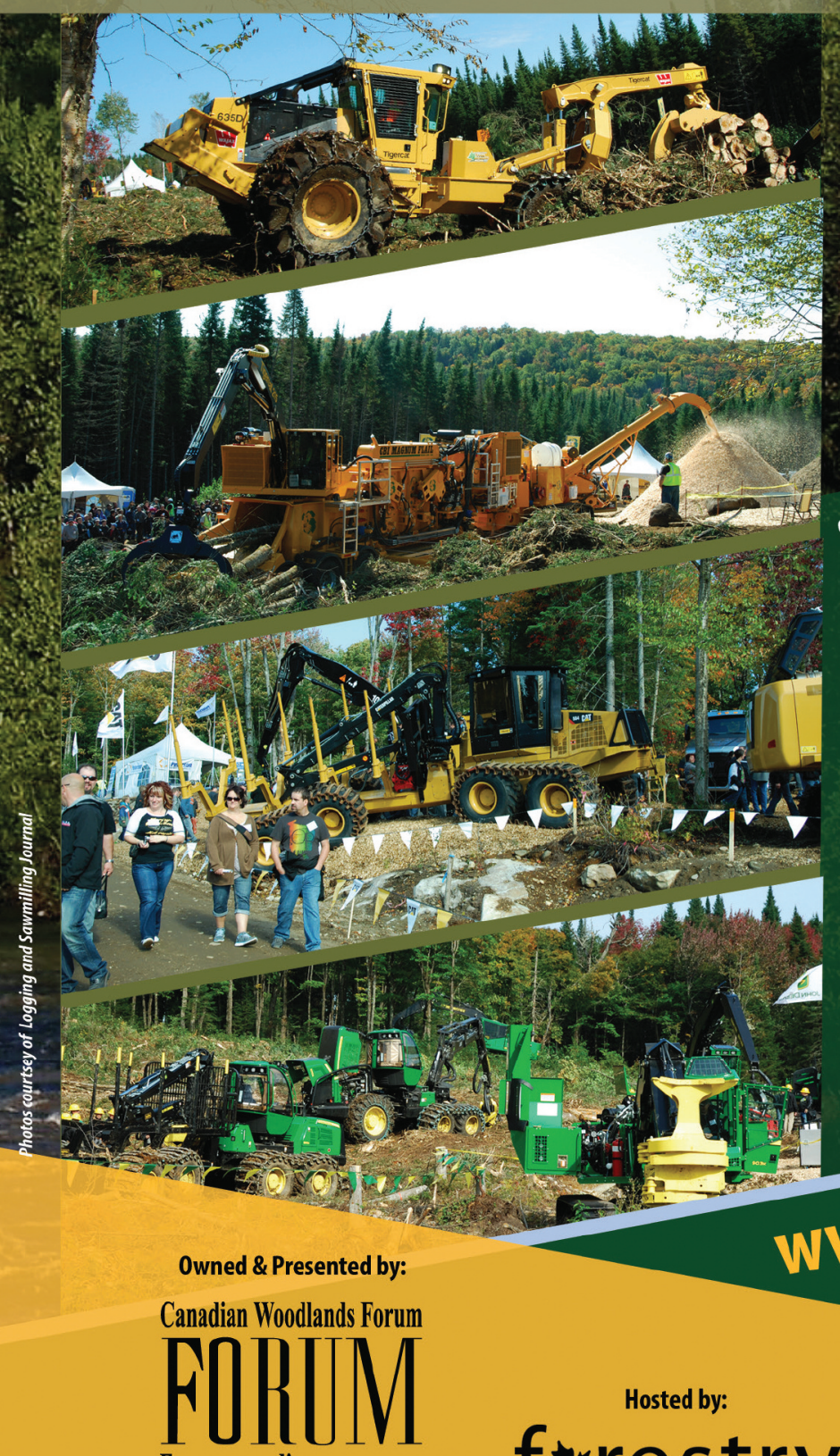

Forum canadien des opérations forestières

$\triangle$

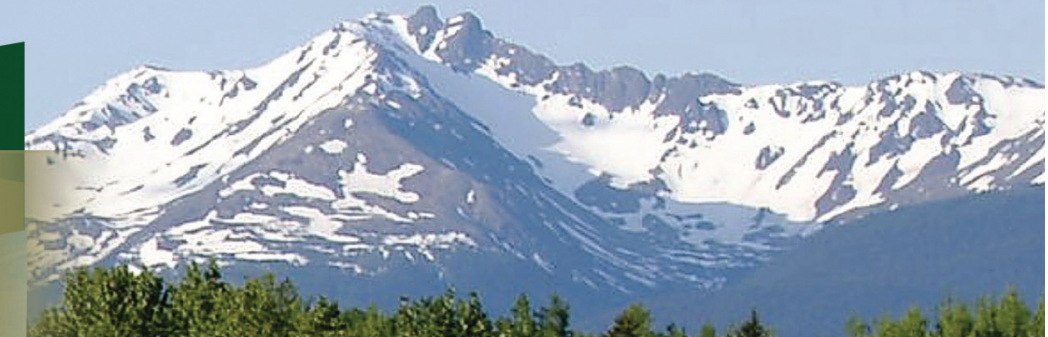

\section{IIIEEOUIPMEII DEDiosintwoons 8LILAIOLI}

SiOW WOULifs Thursday, September 22 9am-5pm
Friday, September 23 9am-5pm Saturday, September 24 9am-4pm

REESTRIITII DIITIE is now open with special pre-show DISCOUNTS offered! Plan your Trip to DEMO International ${ }^{\circledR}$ Early! 